\title{
A SIMPLIFIED PLATE METHOD FOR DETECTING GELATINE-LIQUEFYING BACTERIA
}

\author{
BY \\ SUZANNE K. R. CLARKE \\ From the Department of Pathology, Bristol Royal Infirmary
}

(RECEIVED FOR PUBLICATION MARCH 11, 1953)

Frazier (1926) described a plate method of testing for gelatine liquefaction. The gelatine was incorporated in a low-peptone agar medium. After growing the organism on the medium, the occurrence of digestion was shown by treating the plates with acid mercuric chloride or tannic acid. Frazier claimed that his method was more sensitive and gave quicker results than the usual gelatine "stab" method.

Barer (1946) applied Frazier's method to freshly isolated bacteria from human material (chiefly intestinal Gram-negative bacilli) and found it satisfactory. Smith, Gordon, and Clark (1946) mention a simplification of Frazier's method which they used in examining aerobic sporing bacilli. Gelatine was incorporated in a concentration of $0.4 \%$ in nutrient agar instead of in a specially prepared basal medium. Evans and Wardlaw (1952) tried a similar method, incorporating $0.5 \%$ gelatine in non-nutrient agar, for measuring the gelatinase activity of $B$. subtilis culture filtrates, but found it unsuitable for accurate measurement.

This paper reports an investigation of the simplified method (with a higher concentration of gelatine) which has been used in this laboratory for testing some bacteria of medical importance. The results have been compared with those of stab tests done at the same time.

\section{Method}

The following solutions are prepared: (1) $10 \%$ leaf gelatine $(w / v)$ in distilled water is sterilized by steaming for $\mathbf{3 0}$ minutes on three successive days and stored at $4-6^{\circ} \mathrm{C}$. ; (2) $\mathrm{HgCl}_{2}, 15 \mathrm{~g}$., is dissolved in $20 \mathrm{ml}$. concentrated hydrochloric acid, and water added to make $100 \mathrm{ml}$.

For use, the gelatine is melted in the $37^{\circ} \mathrm{C}$. waterbath. One volume is mixed with 9 volumes of infusion base nutrient agar and plates poured and allowed to set and dry. The organism is streaked or spotted on the surface. Six cultures may be tested on one $3 \frac{1}{2}$-in. plate. The plate is incubated at $37^{\circ} \mathrm{C}$. for two or three days; two days is usually sufficient for intestinal Gram-negative bacilli. If desired, two plates may be inoculated and incubated for different times. is The growth is wiped off with cotton-wool moistened $\vec{f}$ in the $\mathrm{HgCl}_{2}-\mathrm{HCl}$ solution with which the plate is 9 then flooded. Digestion is shown by a clear zone around the colonies on an otherwise densely opaque plate. The high concentration of peptone in nutrient

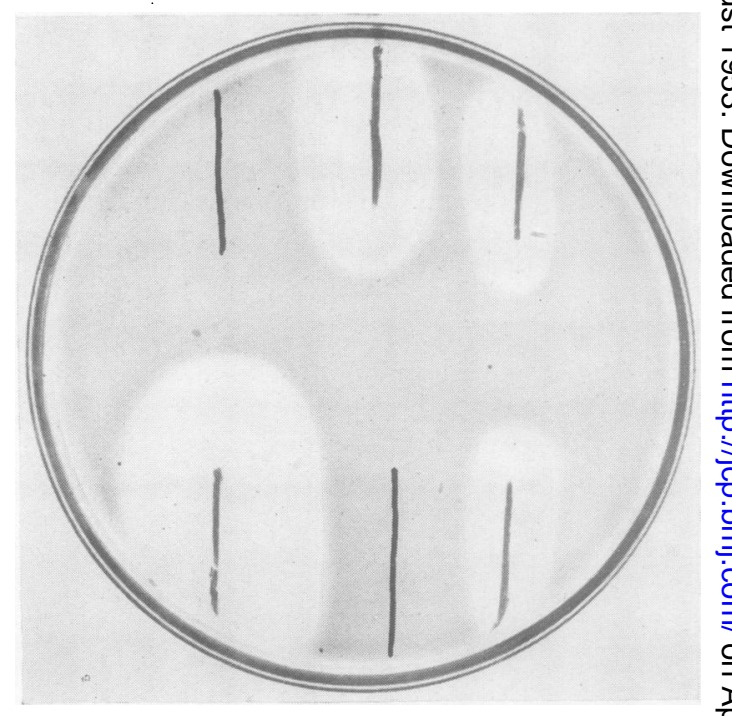

FIG. 1.-Plate after treatment with $\mathrm{HgCl}_{2}$. The pencil lines show where the organisms were growing. The positive strains were
Ps. pyocyanea; the negative strains were Bact. coli.

agar does not affect the results because proteolytic $\widetilde{O}$ organisms digest it as well as the gelatine. No change N in the opacity of the medium around the colony, or a $\omega$ slight change but without distinct clearing, is read as negative. For swarming organisms the agar con- $\stackrel{\varrho}{\varrho}$ tent of the medium is increased to $6 \%$.

The gelatine-nutrient agar plate and stab methods $\stackrel{\mathcal{D}}{+}$ were compared at $37^{\circ} \mathrm{C}$., using a variety of bacilli 0 (70 strains in all), most of which were freshly isolated. For this purpose each strain was inoculated into one $\mathbb{\mathbb { D }}$ stab and streaked on three plates. The plates were $\overrightarrow{\mathbb{D}}$ treated with precipitating fluid after one, three, and $\frac{\varrho}{O}$ five days' incubation respectively. The nutrient gelatine stabs were made from the same batch of gelatine 8 
as the plates by a standard method (Mackie and McCartney, 1948). Inoculated stabs were tested for liquefaction by cooling in the refrigerator after one, three, five, seven, 10 , and 14 days' incubation at $37^{\circ} \mathrm{C}$.

The plate results were found to be the same after five days' incubation as after three days with one exception, a recently isolated V.P.-negative, indol-
Solutions (1) and (2) were mixed and heated in the steamer. Then $500 \mathrm{ml}$. of $3 \%(\mathrm{w} / \mathrm{v})$ agar powder in distilled water was added, the $p \mathrm{H}$ adjusted to 7.0, and the whole autoclaved at $5 \mathrm{lb}$. pressure for 20 minutes.

The following organisms (with numbers of strains in parentheses) were used to compare the two plate methods: Bact. coli (14), Bact. aerogenes (8), Alkaligenes faecalis (8), paracolon strains (4), Salmonellae

TABLE

ANALYSIS OF RESULTS COMPARING THE PLATE AND STAB METHODS

\begin{tabular}{|c|c|c|c|c|c|c|c|c|c|c|c|c|c|}
\hline \multirow{3}{*}{\multicolumn{3}{|c|}{ Organism }} & \multirow{3}{*}{$\begin{array}{l}\text { No. } \\
\text { Tested }\end{array}$} & \multicolumn{3}{|c|}{ Plate Method } & \multicolumn{7}{|c|}{ Stab Method } \\
\hline & & & & \multicolumn{2}{|c|}{ Positive } & \multirow{2}{*}{$\begin{array}{c}\text { Negative } \\
\text { at } \\
3 \text { Days }\end{array}$} & \multicolumn{6}{|c|}{ Positive at (Days) } & \multirow{2}{*}{$\begin{array}{c}\text { Negative } \\
\text { at } \\
14 \text { Days }\end{array}$} \\
\hline & & & & 1 Day* & 3 Days & & 1 & 3 & 5 & 7 & 10 & 14 & \\
\hline $\begin{array}{l}\text { Bact. coli } \\
\text { B. aerogenes } \\
\text { B. cloacae } \dagger \\
\text { Paracolons . . } \\
\text { Proteus vulgari } \\
\text { Proteus mirabil } \\
\text { Proteus morgan } \\
\text { Ps. pyocyanea } \\
\text { Shigella sonnei } \\
\text { Salm. typhi and } \\
\text { Salm. para A } \dagger \\
\text { Salm. schleissh } \\
\text { Salm. abortus b } \\
\text { Clostridium . } \\
\text { Genus bacillus }\end{array}$ & $\begin{array}{l}\ldots \\
\ldots \\
\ldots \\
\ldots \\
\ldots \\
\ldots \\
\ldots \\
\text { teritidis } \\
\text { and C } \dagger \\
+ \\
\text { ist } \\
\ldots \\
\ldots\end{array}$ & $\begin{array}{l}\cdots \\
\cdots \\
\cdots \\
\cdots \\
\cdots \\
\cdots \\
\cdots \\
\cdots \\
\cdots \\
\cdots \\
\cdots\end{array}$ & $\begin{array}{r}15 \\
5 \\
2 \\
2 \\
10 \\
3 \\
8 \\
9 \\
1 \\
2 \\
3 \\
1 \\
1 \\
4 \\
4\end{array}$ & $\begin{array}{l}- \\
\overline{-} \\
\overline{10} \\
\frac{3}{9} \\
\overline{-} \\
\overline{-} \\
1 \\
4 \\
4\end{array}$ & $\begin{array}{l}\bar{z} \\
z \\
\bar{z} \\
\bar{z} \\
\bar{z} \\
\overline{-} \\
-\end{array}$ & $\begin{array}{r}15 \\
5 \\
2 \\
- \\
\frac{1}{2} \\
3 \\
= \\
-\end{array}$ & $\begin{array}{l}- \\
\bar{z} \\
\frac{2}{1} \\
- \\
= \\
-\end{array}$ & $\begin{array}{l}- \\
- \\
8 \\
3 \\
8 \\
- \\
- \\
1 \\
4 \\
1\end{array}$ & $\begin{array}{l}- \\
-1 \\
= \\
= \\
- \\
= \\
= \\
1\end{array}$ & $\begin{array}{l}- \\
z \\
z \\
z \\
z \\
z \\
z \\
z \\
-\end{array}$ & 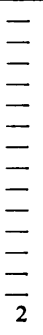 & 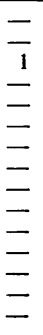 & $\begin{array}{r}15 \\
5 \\
\frac{2}{-} \\
\frac{8}{8} \\
\frac{1}{2} \\
- \\
- \\
-\end{array}$ \\
\hline
\end{tabular}

* The figures under the day columns show the numbers of cultures which became positive for the first time on that day. Strains marked $\dagger$ were obtained from the National Collection of Type Cultures.

and M.R.-positive coliform bacillus which was positive at five days only. This strain did not liquefy a gelatine stab incubated for 28 days.

The results of the comparison are given in the Table. Digestion usually appeared faster on plates than in stabs, but with the exception mentioned above there was complete agreement between the two methods.

Attempts were also made to compare the plate and stab methods using coagulase-positive staphylococci. With these organisms, however, the positive results were often indistinct on the plates and very slow to develop in the stabs. Moreover, the strength of the reaction given by particular strains often varied greatly when re-tested by either method. The plate method was generally the more sensitive. Barer, using Frazier's original plate method, found that results with staphylococci were unsatisfactory.

\section{Comparison with Frazier's Method}

A further series of Gram-negative bacilli was tested in parallel on gelatine-nutrient agar plates and Frazier plates. The latter were prepared as follows:

Solution (1). $-\mathrm{NaCl}, 5$ g., $\mathrm{KH}_{2} \mathrm{PO}_{4}, 0.5$ g., and $\mathrm{K}_{2} \mathrm{HPO}_{4}, 1.5 \mathrm{~g}$., were dissolved in $100 \mathrm{ml}$. distilled water.

Solution (2).-Bacto-gelatine (Difco), 4 g., was dissolved in $400 \mathrm{ml}$. distilled water, and $0.05 \mathrm{~g}$. dextrose, $0.1 \mathrm{~g}$. bacto-peptone, and $5 \mathrm{ml}$. of beef infusion (as used for infusion broth) were then added.
(10), and gelatine-negative Proteus (16) (gelatine nonliquefiers); swarming Proteus (3), Ps. pyocyanea (19) (gelatine liquefiers).

The only discrepancies occurred with the three swarming Proteus strains, which on Frazier plates grew very poorly and did not hydrolyse the gelatine. The growth of all the organisms was comparatively feeble on the Frazier medium and the zones of clearing were often difficult to see.

\section{Discussion}

Tests for gelatine liquefaction are not often required in routine clinical bacteriology, but sometimes they are useful in the identification of atypical Gram-negative bacilli from the intestinal and urinary tracts. It is therefore convenient to have a method which can be used at any time with the minimum of preparation. The modified Frazier method requires only two simple stock solutions, which keep indefinitely. The rather troublesome preparation of gelatine stabs is avoided, and results are obtained more quickly than with stabs and are more distinct than with the original Frazier method. Most of Frazier's organisms were isolated from milk and water. Probably many of them grew better on his medium and gave clearer results than bacteria of animal origin. 


\section{Summary}

An easily prepared plate method for detecting gelatine liquefaction is described. It was compared with the standard stab method, using 70 different organisms, mostly Gram-negative bacilli, from pathological material. With one exception there was complete agreement in results between the two methods, the plate method giving the results more quickly.

The plate method was also compared with Frazier's plate method, using 82 strains of Gram- negative bacillus. The only discrepancy in results occurred with spreading Proteus strains, which $\stackrel{\vec{\rho}}{\vec{\rho}}$ failed to hydrolyse gelatine in the Frazier plates.

I am indebted to Dr. W. A. Gillespie for much advice and encouragement.

\section{REFERENCES}

Barer, Gwendoline (1946). Monthly Bull. Minist. Hlth, Lond., 5, 28. Evans, D G and Wardlaw, A C. (1952) J.gen. Microbiol., 7, 397 Frazier, W. C. (1926). J. infect. Dis., 39, 302.

Mackie, T. J., and McCartney, J. E. (1948). Handbook of Practical $\vec{\circ}$ Bacteriology, 8th ed., p. 147. Livingstone, Edinburgh.

Smith, N. R., Gordon, R. E., and Clark, F. E. (1946). Mesophilic Sporeforming Bacteria. United States Department of Agriculture, Misc. Publication No. 559, p. 33. 